


\title{
LOS DERECHOS AL DEBIDO PROCESO Y \\ ACCESO A LA ADMINISTRACIÓN DE JUSTICIA EN LOS CASOS DE RESTITUCIÓN DEL INMUEBLE ARRENDADO: LA RATIO DECIDENDI DE LA CORTE CONSTITUCIONAL (Col).
}

\author{
Karen Ferlen Vargas Rincón \\ Abogada, Esp. Derecho Procesal, Universidad Santo Tomás-Bucaramanga (Col). \\ Consultorio Jurídico, Universidad Santo Tomás, Bucaramanga \\ E-mail: karenvargasrincon@hotmail.com \\ Silvia Juliana Evan Martínez \\ Abogada, Esp. Derecho Procesal, Universidad Santo Tomás-Bucaramanga (Col). \\ Consultorio Jurídico, Universidad Santo Tomás, Bucaramanga \\ E-mail:evans8615@hotmail.com \\ María Cristina Navarro Valenzuela \\ Abogada, Esp. Derecho Procesal, Universidad Santo Tomás-Bucaramanga (Col). \\ Consultorio Jurídico, Universidad Santo Tomás, Bucaramanga \\ E-mail:mariacris43@hotmail.com
}

\begin{abstract}
Resumen
El presente trabajo establece los criterios más utilizados por la Corte Constitucional en sus sentencias, en materia de vulneración del derecho fundamental al debido proceso y acceso a la administración de justicia desde el marco de la restitución de inmuebles en casos en que se dude sobre la existencia del contrato de arrendamiento durante el periodo 2004 - 2007. Se presenta un acercamiento a los conceptos básicos de "debido proceso" y "acceso a la administración de justicia" desde el punto de vista doctrinal y jurisprudencial. El texto se desarrolla en tres momentos contextualizados por jurisprudencias de la Corte, el primero identifica las causas que genera la violación a los derechos fundamentales al debido proceso y acceso a la administración de justicia, el segundo plantea los motivos que han llevado a los jueces de instancia a negar o conceder la acción de tutela y el tercer momento, reconoce las situaciones fácticas en los cuales es procedente el mecanismo constitucional.
\end{abstract}

\section{Palabras clave}

Debido proceso, acceso a la administración de justicia, Corte Constitucional, contrato de arrendamiento, acción de tutela y ratio decidendi.

\begin{abstract}
The present work establish the most used criteria in the jurisprudence of the Constitutional Court about the vulnerability of the fundamental right to due process and access to the administration of justice within the framework of real state restitution processes in cases where there is a doubt about the existence of the renting contract, judicial decision on the period between $2004-2007$. The authors make a close up to the basic concepts of "due process" and "access to the administration of justice" from the doctrinal and jurisprudential point of view. This paper develop three moments contextualized by the jurisprudence of the Court, the first on identifies the causes that generate the violation of the fundamental rights to due process and access to the administration of justice. The second comes up with the motives that have driven the judges to deny or grant the writ for protection of fundamental rights, and the third moment recognizes the factual situation in which the constitutional action can be admitted.
\end{abstract}

\section{Key Words}

Due process, Access to justice, Constitutional Court, real state restitution process, renting contract, share custody and ratio decidendi 

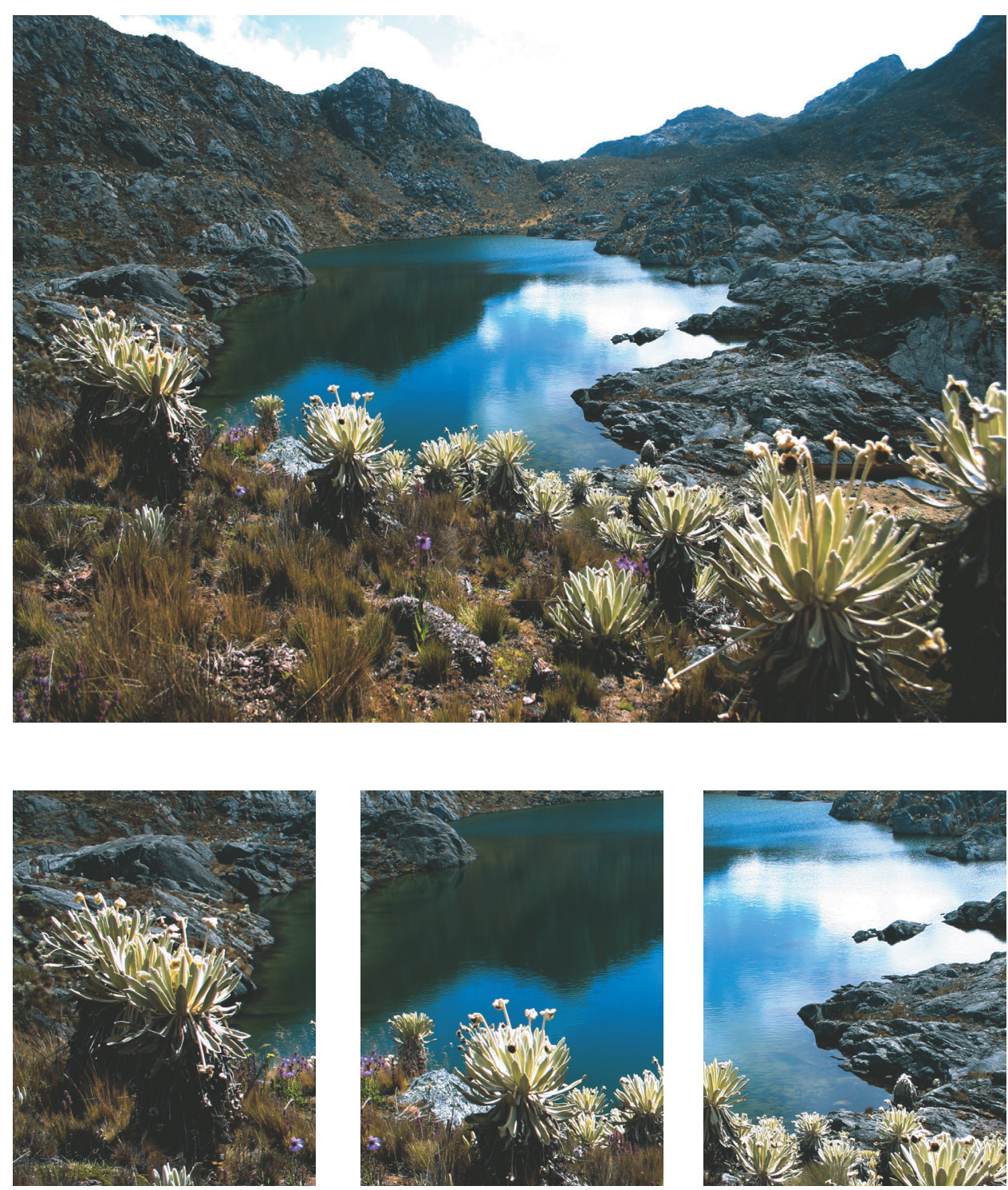

"Laguna Verde de Morro Nevado" 


\section{LOS DERECHOS AL DEBIDO PROCESO Y ACCESO A LA ADMINISTRACIÓN DE JUSTICIA EN LOS CASOS DE RESTITUCIÓN DEL INMUEBLE ARRENDADO: LA RATIO DECIDENDI DE LA CORTE CONSTITUCIONAL (COL)*}

Karen Ferlen Vargas Rincón

Silvia Juliana Evan Martínez Ma. Cristina Navarro Valenzuela

A través del presente escrito, se pretende determinar cuáles son los criterios comunes presentes en la jurisprudencia emitida por la Corte Constitucional durante el periodo 2004-2007, respecto a la vulneración del derecho fundamental al debido proceso y acceso a la administración de justicia dentro del proceso de restitución de inmueble arrendado, en aquellos casos en que se presenta duda sobre la existencia del contrato de arrendamiento.

El tema encuentra sustento en el numeral 2 del Parágrafo 2 del artículo 424 del Código de Procedimiento Civil (CPC), al indicar que:

"el demandado no será oído en el proceso hasta tanto demuestre que ha consignado a órdenes del juzgado el valor total que de acuerdo con la prueba allegada con la demanda, tienen los cánones adeudados, o en defecto de lo anterior, cuando presente los recibos de pago expedidos por el arrendador correspondientes a los tres últimos períodos, o si fuere el caso los correspondientes de las consignaciones efectuadas de acuerdo con la ley y por los mismos períodos, en favor de aquel".

El artículo reflexiona sobre el Debido Proceso y el Acceso a la Administración de Justicia. El ejercicio se desarrolla en el marco de la asignatura de Metodología de la Investigación (Asesor Docente Javier Díaz Díaz) de la Especialización en Derecho Procesal Cohorte III - Universidad Santo Tomás-Seccional Bucaramanga. 
Para la aplicación de la norma descrita, es necesaria la existencia previa de un contrato de arrendamiento, sin embargo, existen eventos en los cuales dicha situación fáctica no se configura, y pese a ello, los operadores judiciales de manera estricta hacen uso de la consecuencia jurídica establecida en el precepto legal, cual es, la emisión de una sentencia en la que se ordena la entrega del inmueble objeto del arrendamiento, sin que anteriormente se haya escuchado al demandado, de esta manera vulnera sus derechos fundamentales al debido proceso y acceso a la administración de justicia, plasmados en los artículos 29 y 229 de la Carta Maga, respectivamente. Por lo anterior, la acción de tutela se ha convertido en el mecanismo utilizado por el demando para lograr que el funcionario judicial analice concienzudamente el caso sometido a su decisión, y en consideración a la realidad fáctica en que se encuentra.

Precisamente la Corte Constitucional, que actúa como Tribunal de cierre de la Jurisdicción Constitucional, y busca solucionar el conflicto que se genera entre la norma procesal y los presupuestos fácticos para su aplicación, ha desarrollado a través de sus providencias criterios referentes a la inaplicación del artículo en mención; los cuales, mediante el presente escrito se darán a conocer, con el objetivo de lograr que los jueces hagan uso de la ley de manera reflexiva e interpretativa, al escudriñar cada caso en particular. No obstante, no sólo el operador judicial debe conocer dichos razonamientos, sino también la comunidad jurídica y académica, de tal suerte que el alcance y la interpretación que debe existir del artículo 424 del CPC, sea exigido por la colectividad en general, mediante los diferentes mecanismos que el orden jurídico brinde, para lograr que el juez no extienda consecuencias jurídicas a un supuesto de hecho que no está contenido en la ley; y sobrepase sus facultades constitucionales y legales. Lo anterior, permitirá que los criterios jurisprudenciales desarrollados por las distintas Salas de Revisión de la Corte, sean adoptados y aplicados por parte del juez natural del proceso, sin necesidad que el arrendatario demandado, en el evento en que exista duda sobre la existencia del contrato de arrendamiento, acuda a la acción de tutela como mecanismo de protección de sus derechos fundamentales.

Para cumplir con el objetivo planteado es necesario desarrollar tres procedimientos: primero, identificar las causas generadoras de violación a los derechos fundamentales al debido proceso y acceso a la administración de justicia dentro del trámite del proceso de restitución de inmueble arrendado a través de los casos analizados por la Corte Constitucional; segundo, identificar los motivos que han llevado a los jueces de instancia a negar o conceder la acción de tutela como mecanismo para proteger los derechos fundamentales en la eventualidad bajo estudio y por último, identificar las situaciones fácticas en las cuales es procedente el mecanismo constitucional.

Para lo anterior, y con el fin que sea de fácil entendimiento el tema, se procederá a precisar aquellos conceptos que son el eje central del canon cuestionado.

En primer lugar, encontramos el referente a contrato de arrendamiento, cuya definición se encuentra contemplado en el artículo 1973 del Código Civil de la siguiente manera, 
"El arrendamiento es un contrato en que las dos partes se obligan recíprocamente, la una a conceder el goce de una cosa, o a ejecutar una obra o prestar un servicio, y la otra a pagar por éste goce, obra o servicio un precio determinado";

es decir, en palabras del tratadista César Gómez Estrada:

"el contrato de arrendamiento es aquel en virtud del cual una de las partes se obliga a proporcionar a la otra el goce de una cosa durante cierto tiempo, y ésta a pagar por dicho goce un precio determinado" (Gómez, 2008, 196).

De las definiciones anotadas, se puede extraer que los elementos esenciales del contrato de arrendamiento son dos:

a. Cosa arrendada: Según César Gómez Estrada la cosa arrendada hace relación "al bien que el arrendador entrega al arrendatario para que éste lo disfrute"; así mismo (...): "La cosa arrendada debe existir en el momento de perfeccionarse el contrato o, por lo menos, debe tratarse de cosa que se espera que exista, en cuyo caso el contrato queda sujeto a la condición de que la cosa llegue a existir, como para el mismo evento lo dispone el artículo 1869 respecto al contrato de venta" (Gómez, 2008, 202).

b. Precio: En relación al precio Gómez Estada plantea que... "El precio puede consistir en dinero o en frutos naturales de la cosa arrendada. Cuando consiste en frutos de la cosa arrendada, puede determinarse en dos formas: o en una cantidad cierta y fija de frutos, como tantas arrobas de café, o en una cuota proporcional de los frutos que produzca el inmueble, como la mitad, la tercera, o la cuarta parte que se perciba en cada cosecha" (Gómez, 2008, 204).

Con base en lo anterior, es válido establecer que el contrato de arrendamiento es una relación contractual en la cual se derivan obligaciones para ambas partes, arrendador y arrendatario (previstas en el artículo 1982 y 1996 del CC), donde el primero se apersona de la entrega, las reparaciones y mantenimientos de la cosa arrendada, y el segundo del uso de la cosa, reparaciones y pago de los cánones de arrendamiento, entre otras. Las obligaciones mencionadas se encuentran contempladas principalmente en el código civil, código de comercio y en la ley 820 de 2003, por la cual se regula el contrato de arrendamiento de vivienda urbana.

De las obligaciones más importantes, y que para el caso concreto nos interesa, se encuentra la consagrada en el inciso 1 del artículo 2000 del Código Civil, cuando estipula que "el arrendatario es obligado al pago del precio o renta". El incumplimiento de esta obligación es una causal para la terminación del contrato de arrendamiento de manera unilateral por parte del arrendador y, por ende, lo legitima para solicitar vía judicial la restitución del inmueble entregado en arrendamiento. De tal importancia es la nombrada obligación, que el artículo 424 del Código de Procedimiento Civil (CPC) modificado por el artículo 44 de la ley 794 de 2003, en el que se regula el proceso de restitución de inmueble arrendado, le impone al arrendatario demandado la carga procesal de demostrar el pago de los cánones de 
arrendamiento supuestamente adeudados, cuando ésta es la causal de la restitución. La norma lo regula de la siguiente manera:

"Si la demanda se fundamenta en falta de pago, el demandado no será oído en el proceso sino hasta tanto demuestre que ha consignado a órdenes del Juzgado el valor total que de acuerdo con la prueba allegada con la demanda, tienen los cánones adeudados, o en defecto de lo anterior, cuando presente los recibos de pago expedidos por el arrendador correspondientes a los tres últimos períodos, o si fuere el caso los correspondientes de las consignaciones efectuadas de acuerdo con la ley y por los mismos períodos, en favor de aquel."

Otro de los conceptos para tener en cuenta es el de Proceso de restitución del inmueble arrendado, el cual es tradicionalmente conocido con el nombre de "lanzamiento de arrendatario", por ser esa la denominación legal empleada antes de la entrada en vigencia del decreto 2282 de 1989, que lo consagró como el trámite único para toda clase de procesos de restitución de tenencia, sea de vivienda, locales comerciales o de bienes muebles. Su finalidad, es

"la restitución de la tenencia otorgada por el arrendador al arrendatario y las indemnizaciones a que haya lugar, y no el pago de los cánones adeudados o de multas pactadas en caso de incumplimiento, los cuales se pueden hacer efectivos por un proceso de ejecución independiente si es antes de proferida la sentencia estimatoria de la demanda siempre y cuando el contrato reúna los requisitos propios de un título ejecutivo o ante el mismo juez si es después, además se persigue con esa actuación tal como lo señala el numeral 9 del artículo 408, el reconocimiento de las indemnizaciones a que hubiere lugar" (LÓPEZ. 2004, 179).

Una vez precisados los conceptos mencionados, igualmente es necesario traer a colación las normas constitucionales que servirán de fuente para el desarrollo del objetivo propuesto. La primera de ellas hace relación al derecho de acceso a la administración justicia, que se encuentra plasmada en el Artículo 228 y 229 de la Constitución Política de Colombia, de la siguiente manera:

“Artículo 228. La Administración de Justicia es función pública. Sus decisiones son independientes. Las actuaciones serán públicas y permanentes con las excepciones que establezca la ley y en ellas prevalecerá el derecho sustancial. Los términos procesales se observarán con diligencia y su incumplimiento será sancionado. Su funcionamiento será desconcentrado y autónomo”(...).

(...)"Artículo 229. Se garantiza el derecho de toda persona para acceder a la administración de justicia. La ley indicará en qué casos podrá hacerlo sin la representación de abogado."

A su vez el artículo 29 de la Carta Magna, consagra el derecho fundamental al debido proceso estableciendo que:

"El debido proceso se aplicará a toda clase de actuaciones judiciales y administrativas (...) Nadie podrá ser juzgado sino conforme a las leyes preexistentes al acto que se le imputa, ante juez o tribunal competente y con observancia de la plenitud de las formas propias de cada juicio"(...). 
(...) "En materia penal, la ley permisiva y favorable, aún cuando sea posterior, se aplicará de preferencia a la restrictiva o desfavorable"(...).

(...) "Toda persona se presume inocente mientras no se la haya declarado judicialmente culpable. Quien sea sindicado tiene derecho a la defensa y a la asistencia de un abogado escogido por él o de oficio, durante la investigación y el juzgamiento; a un debido proceso público sin dilaciones injustificadas; a presentar pruebas y controvertir las que se alleguen en su contra; a impugnar la sentencia condenatoria, y a no ser juzgado dos veces por el mismo hecho. Es nula, de pleno derecho, la prueba obtenida con violación del debido proceso".

Estos aspectos mencionados son considerados la base normativa fundamental que orienta el debido proceso y, por esta razón, hay que tenerlas como parámetro orientador de la labor jurídica.

Por otra parte, se hará uso de varios artículos académicos, que proporcionarán las herramientas suficientes para comprender el alcance actual y el nuevo rol del derecho procesal, al convertirse en garante de igualdad, justicia y, ante todo, constructor del derecho sustancial. Entre los artículos referidos se encuentra: "El Debido Proceso", elaborado por el profesor Martín Agudelo Ramírez, en él se establece que:

"El debido proceso permite que el proceso incorpore las referidas aspiraciones de derecho justo, exigiendo el desarrollo de unos procedimientos equitativos en los que sus participantes deben ser escuchados en términos razonables. Se revela asi un gran instrumento tutelar de participación encaminado a brindar tutela concreta o protección jurídica de los derechos sustantivos sin consumar el de imperio de los fuertes sobre los más débiles" (AGUDELO, 2005, 89).

Aquí el derecho fundamental al debido proceso es presentado como aquel que exige procedimientos pluralistas y participativos, en los que se garanticen la igualdad y un debate que permita la defensa de todos sus participantes. En conclusión, se afirma que el derecho procesal debe enlazarse al derecho constitucional, lo que sólo logrará a través del derecho fundamental al debido proceso, tal como lo mencionó el autor al manifestar que:

"el derecho procesal no se agota en las meras formas, sino que se orienta por la justicia, siendo el debido proceso base primordial de su transformación". (Agudelo, 2005, 92).

Así, para el autor, el derecho procesal debe convertirse en un espacio claro para la obtención de un derecho justo, mediante la intervención de los participantes en la igualdad y el reconocimiento mutuo y donde el operador judicial acceda a las vías del discurso y la argumentación. 
Por otra parte, se encuentra el artículo ¿Qué hacer con la tutela contra sentencias? de Mauricio García Villegas y Rodrigo Uprimmy, en él se presenta la problemática actual ante el masivo uso de la acción de tutela contra providencias judiciales, situación que ha llevado a considerar que esta figura deba ser eliminada para tal fin. Las posiciones, a favor y en contra, son presentadas en el documento, sin embargo, lo importante es la propuesta que se realiza para racionalizar el uso del mencionado mecanismo constitucional de protección a los derechos fundamentales. Los detractores de la acción de tutela utilizan como argumento la defensa de la seguridad jurídica, de la autonomía judicial, del principio del juez natural y finalización definitiva de las controversias. Como argumento a favor se establece que la acción de tutela está:

"encaminada a cumplir dos finalidades complementarias: de un lado, pretende evitar errores judiciales graves, que vulneren derechos fundamentales. $Y$, de otro lado, la tutela permite una constitucionalización coherente del ordenamiento jurídico en la medida en que permite unificar la interpretación sobre el alcance de los derechos fundamentales" (García, 2004, 100).

Otro artículo académico relevante dentro del cuerpo de la investigación, es el denominado "La protección procesal de los derechos fundamentales" del profesor Cipriano Gómez Lara. En síntesis, el documento presenta al derecho procesal como:

"un instrumento protector de derechos, un conjunto completo de actos, del Estado soberano, de las partes a través de sus acciones, excepciones $y$ defensas, $y$ de terceros ajenos a la relación sustancial, actos todos encaminados y proyectados a la aplicación de una norma general a un caso concreto controvertido para dirimirlo o solucionarlo" (Gómez Lara, 1990, 286).

Por último, se analiza el artículo, A propósito de la justica material (reflexiones sobre la justicia en el proceso vs. La justicia material) de Diana María Ramírez Carvajal (Ramírez, 2007, 165). En él se retoma el criterio de la Corte Constitucional respecto a la prevalencia del derecho sustancial sobre los formalismos o rigorismos, para enseñar la noción actual del derecho procesal, cuya función, desde la Constitución inicia en el debido proceso y alcanza un nivel de garantía cuando logra establecerse como derecho fundamental. Uno de los cambios se da en su naturaleza jurídica convirtiéndose en mixta donde el debido proceso es no sólo un derecho sino un fin en sí mismo, ya que cada uno de los principios que lo componen puede ser reclamado por cualquier persona de manera individual o colectiva y tiene una protección prevalente; además el debido proceso también goza de naturaleza instrumental porque permea todos los procedimientos lo cual permite alcanzar con efectividad otros derechos que han sido vulnerados.

Una vez precisado los insumos teóricos que guiarán al marco analítico del presente artículo académico, se procederá a presentar los fundamentos que darán cuerpo a la solución de la problemática planteada.

En primer lugar, es preciso definir el alcance que actualmente ha adquirido dentro del sistema de fuentes del derecho nacional, la jurisprudencia emitida por la 
Honorable Corte Constitucional como guardiana de la integridad y supremacía de la Constitución Política. La Carta Magna en su artículo 230 le otorga a la jurisprudencia la función de servir como criterio auxiliar en la actividad judicial, al consagrar que los jueces en sus providencias solo se encuentran sometidos al imperio de la ley. Sin embargo, la misma Corte en uso de la potestad de fijar el alcance de sus propios fallos, determinó el grado de obediencia a los mismos con base en el tipo de sentencia por ella emitida. Así las cosas, en las sentencias de constitucionalidad; es decir, aquellas en las cuales se estudia si una norma legal se ajusta a la Constitución Política y, por tanto debe permanecer en el ordenamiento jurídico, son de carácter obligatorio la parte resolutiva y aquellos conceptos que se encuentran consignados en la parte motiva y guardan una relación estrecha con la decisión. Los conceptos referidos se denominan ratio decidendi, mientras que aquellos apartes irrelevantes del fallo se llaman obiter dictum. La Corte, al revisar la constitucionalidad del artículo 48 de la ley estatutaria de administración de justicia mediante sentencia C-037-1994, concluyó respecto al tema de la siguiente manera:

"sólo será de obligatorio cumplimiento, esto es, únicamente hace tránsito a cosa juzgada constitucional, la parte resolutiva de las sentencias de la Corte Constitucional. En cuanto a la parte motiva, como lo establece la norma, esta constituye criterio auxiliar para la actividad judicial y para la aplicación de las normas de derecho en general; sólo tendrían fuerza vinculante los conceptos consignados en esta parte que guarden una relación estrecha, directa e inescindible con la parte resolutiva; en otras palabras, aquella parte de la argumentación que se considere absolutamente básica, necesaria e indispensable para servir de soporte directo a la parte resolutiva de las sentencias y que incida directamente en ella". (Corte Constitucional. Sentencia C-037 de 1994, M.P. Antonio Barrera Carbonell).

Al respecto no existe discusión alguna, pues indudablemente autoridades públicas y ciudadanos se encuentran sujetos a la permanencia de la norma luego de la decisión de constitucionalidad consignada en la parte resolutiva y en aquellas motivaciones que guardan unidad de sentido con el dispositivo de la sentencia. El punto neurálgico surge con relación a las sentencias de tutela. En principio, la parte motiva de los fallos de tutela emitidos por la Corte sólo constituye criterio auxiliar para la actividad de los jueces, así como la decisión o parte resolutiva, es de obligatorio cumplimiento únicamente para las partes intervinientes en el proceso, tal como lo establece el artículo 36 del decreto 2591 de 1991 al expresar que "las sentencias en que se revise una decisión de tutela sólo surtirán efectos en el caso concreto (...)”. Al respecto, la Corte Constitucional en la sentencia C-037-1996 referida en líneas precedentes ultimó:

"Sin embargo, la doctrina constitucional que define el contenido y alcance de los derechos constitucionales, sentada por la Corte Constitucional, con ocasión de la revisión de los fallos de tutela, trasciende las situaciones concretas que le sirven de base y se convierte en pauta que unifica y orienta la interpretación de la Constitución. El principio de independencia judicial, 
tiene que armonizarse con el principio de igualdad en la aplicación del derecho, pues, de lo contrario, se corre el riesgo de incurrir en arbitrariedad. La jurisprudencia de los altos órganos jurisdiccionales, por medio de la unificación doctrinal, persigue la realización del principio de igualdad. Por consiguiente, sin perjuicio de lo observado respecto de la doctrina constitucional, la exequibilidad del segundo numeral del artículo 48, materia de examen, se declarará bajo el entendido de que las sentencias de revisión de la Corte Constitucional, en las que se precise el contenido y alcance de los derechos constitucionales, sirven como criterio auxiliar de la actividad de los jueces, pero si éstos deciden apartarse de la línea jurisprudencial trazada en ellas, deberán justificar de manera suficiente y adecuada el motivo que les lleva a hacerlo, so pena de infringir el principio de igualdad". (Corte Constitucional. Sentencia C-037 de 1996, M.P. Vladimiro Naranjo Mesa).

Con base en lo anterior, es posible afirmar que la Corte Constitucional mediante la revisión de acciones de tutela ha fijado el alcance de los derechos fundamentales, de tal manera que el operador judicial al momento de aplicar un precepto legal haga efectivo los mandatos constitucionales consignados en la Carta Magna, mediante la utilización de la doctrina constitucional decantada en la jurisprudencia emitida por el máximo guardián de la Constitución Política. Por lo anterior, es preciso traer a colación un aparte de la sentencia T-292-2006, en la que se define el valor vinculante que asumen las motivaciones de un fallo de tutela. "Providencias ulteriores, han reconocido naturalmente además el valor vinculante de la ratio decidendi en materia de tutela. De hecho, se ha concluido que en caso de discrepancia entre otras autoridades y esta Corporación frente a interpretaciones constitucionales, prevalecen las consideraciones fijadas por la Corte Constitucional en razón de su competencia de guarda de la supremacía de la Carta. "en caso de que exista un conflicto en torno al alcance de una disposición constitucional entre el desarrollo normativo expedido por el Congreso y la interpretación efectuada por la Corte, prevalece la interpretación de esta última, por cuanto ella es la guardiana de la Carta, y por ende su interpretación constitucional funge como auténtica dentro del ordenamiento jurídico colombiano". Puede concluirse que la ratio decidendi de los fallos de tutela resulta vinculante para los jueces. La razón del valor vinculante de la ratio decidendi en materia de tutela, es asegurar la unidad en la interpretación constitucional en el ordenamiento y un tratamiento en condiciones de igualdad frente a la ley, por parte de las autoridades judiciales, que asegure la seguridad jurídica". (Corte Constitucional. Sala Tercera de Revisión. Sentencia T-292 de 2006, M.P. Manuel José Cepeda Espinosa).

Corolario de lo anterior, el operador judicial se encuentra vinculado a la aplicación de la ratio decidendi en aquellos casos en que adquiere la connotación de precedente judicial, precisamente porque la parte motiva directamente relacionada con la decisión, y en la que se determinó el alcance de un derecho fundamental, puede ser utilizada nuevamente en un caso posterior y similar en su contenido fáctico o problema jurídico. Con el propósito de aclarar el punto, se precisa el concepto de 
precedente judicial con base en la sentencia T-292-2006, en la que se define como "aquella sentencia anterior y pertinente cuya ratio conduce a una regla prohibición, orden o autorización- determinante para resolver el caso, dados unos hechos y un problema jurídico, o una cuestión de constitucionalidad específica, semejantes".

El precedente judicial puede ser vertical u horizontal. El primero implica el sometimiento de jueces y tribunales a la interpretación vinculante que realiza la Corte Constitucional en sus providencias, y el segundo:

(...) "implica el deber que tienen jueces y tribunales de ser consistentes con sus decisiones previas, de modo tal que no sea posible que casos iguales sean resueltos de manera distinta por un mismo juez, estableciéndose como mecanismo de protección y salvaguarda del derecho a la igualdad de trato jurídico de las sentencias de reiteración, las de unificación, y el mecanismo de revisión de los fallos de tutela." (QUINCHE, 2007, 166)

Es aceptable para el funcionario judicial apartarse del precedente, siempre que de manera contundente y razonada argumente los motivos que lo conducen a alejarse de las decisiones anteriores. La carga argumentativa impuesta al juez, debe demostrar que el precedente es contrario a la Constitución Política, en todo o en parte, con el objetivo de validar el distanciamiento. No obstante, existen otras razones señaladas por la Corte en sentencia SU-047 de 1999, para inaplicar el precedente;

(...) "1) eventuales equivocaciones jurisprudenciales del pasado que hacen necesaria la corrección de una línea jurisprudencial; 2) una interpretación que habiendo sido útil y adecuada para resolver ciertos conflictos, en su aplicación actual, puede provocar consecuencias inesperadas e inaceptables en casos similares. 3) Cambios históricos frente a los que resulta irrazonable adherir a la hermenéutica tradicional". (Corte Constitucional. Sentencia SU 047 de 1999).

En pronunciamientos posteriores traídos a colación en la sentencia enunciada, la Corte de igual manera complementó las razones referidas de la siguiente manera:

"cuando los hechos en el proceso en estudio se hacen inaplicables al precedente concreto o cuando "elementos de juicio no considerados en su oportunidad, permiten desarrollar de manera más coherente o armónica la institución jurídica" o ante un tránsito legislativo o un cambio en las disposiciones jurídicas aplicables, circunstancias que pueden exigir una decisión fundada en otras consideraciones jurídicas". (Corte Constitucional. Sentencia SU 047 de 1999).

Al continuar con las anotaciones realizadas hasta el momento, es preciso destacar la importancia de conocer los eventos en que el operador judicial puede distanciarse de la ratio decidendi. Existen situaciones en que es procedente la acción de tutela

1 Corte Constitucional. Sala Tercera de Revisión. Sentencia T-292 de 2006, M.P. Manuel José Cepeda Espinosa. 
contra providencias judiciales, con base en determinadas causales de procedibilidad desarrolladas por la Corte, para el caso que nos interesa; el defecto sustancial, que se estructura

"porque el contenido de la disposición no tiene conexidad material con los presupuestos del caso, o cuando se desconoce el precedente judicial sin ofrecer un mínimo razonable de argumentación, que hubiese permitido una decisión diferente si se hubiese acogido la jurisprudencia"

Para la situación bajo estudio, el máximo Tribunal Constitucional con ocasión a la revisión de acciones de tutela, ha decantado el alcance de los derechos fundamentales al debido proceso y acceso a la administración de justicia al momento de aplicar el parágrafo 2 del artículo 424, del Código de Procedimiento Civil; norma que le exige al arrendatario demandado, con el objetivo de lograr ser escuchado durante el proceso judicial y hacer efectivo su derecho de defensa, demostrar que canceló las prestaciones supuestamente adeudadas antes de la presentación de la demanda, cuando la causal alegada para solicitar la restitución del inmueble es la mora en el pago del canon de arrendamiento.

Precisamente el problema que se pretende abordar en el presente escrito, es determinar cuáles son los criterios comunes en la jurisprudencia emitida por la Corte Constitucional durante el periodo 2004-2007, respecto a la vulneración del derecho fundamental al debido proceso y acceso a la administración de justicia dentro del proceso de restitución de inmueble arrendado, en aquellos casos en que se presenta duda sobre la existencia del contrato de arrendamiento; en otras palabras, se pretende conocer la ratio decidendi fundamento de las decisiones de la Corte, y que han llevado a proteger los derechos conculcados por la norma procesal.

Para lo anterior, se identifican las causas generadoras de violación a los derechos fundamentales durante el trámite procesal, mediante el estudio de los casos resueltos por la Corte, y emitidos con posterioridad al análisis de constitucionalidad efectuado a la norma mediante sentencia C-070/93. La mencionada providencia, declara exequible el numeral 2 del parágrafo 2 del artículo 424 del CPC, pese a los argumentos de inconstitucionalidad esgrimidos por el accionante. La Corte sustentó principalmente su decisión, manifestando que:
"la exigencia impuesta por el legislador al arrendatario demandado responde a las reglas generales que regulan la distribución de la carga de la prueba, se muestra razonable con respecto a los fines buscados por el legislador y no es contraria a las garantías judiciales del debido proceso consagradas en la Constitución y los tratados internacionales que guían la interpretación de los derechos fundamentales". ${ }^{3}$

Lo anterior significa, que cuando la causal aducida por el demandante para lograr

2 Corte Constitucional. Sala Séptima de Revisión. Sentencia T-1082-2007; M.P. Humberto Antonio Sierra Porto.

3 Corte Constitucional. Sala Plena. Sentencia C-070 de 1993; M.P. Eduardo Cifuentes Muñoz. 
la restitución del inmueble es el no pago del canon de arrendamiento, le corresponde desvirtuar la causal al demandado por tratarse de un hecho negativo o indefinido. En esa medida, el arrendatario sólo deberá presentar los recibos o consignaciones adeudadas como requisito procesal para rendir sus descargos, situación que le imprime mayor eficacia y celeridad al trámite judicial.

Como se observa, la Corte encontró ajustado a la Constitución Política el precepto en cuestión y, por ende, a los derechos fundamentales al debido proceso y acceso a la administración de justicia. Pese a ello, múltiples han sido las acciones de tutela mediante las cuales se ha buscado otorgar protección a los derechos mencionados; aparentemente respetados por la norma. La ratio decidendi aducida por la Corte Constitucional para reevaluar su criterio se procede a estudiar a continuación.

La sentencia T-830 de 2004 de la Corte Constitucional; M.P.(E) Rodrigo Uprimny Yepes, una de las primeras providencias en las cuales se vislumbra el criterio de la Corte Constitucional respecto al tema, analiza el caso de una madre cabeza de familia que acuerda con el padre de su menor hija habitar uno de los inmuebles de su propiedad, como forma de pago de la cuota alimentaria a la que previamente se había obligado mediante acta de conciliación. Sin embargo, el progenitor de la menor incumple el acuerdo mencionado, e inicia proceso de restitución de inmueble arrendado con el propósito de desalojarlas. En la demanda, efectivamente se aportó el contrato de arrendamiento suscrito entre las partes, empero adujo la demandada, que si bien suscribió el contrato de arrendamiento, sólo lo hizo con el propósito de colaborarle a su ex compañero sentimental a efectuar oposición en una diligencia de embargo y secuestro en calidad de tenedora, en virtud de un proceso ejecutivo que se adelantaba en su contra.

En este caso, el juez que conoció el proceso de restitución de inmueble, emitió sentencia a favor del demandante, adujo que la celebración del contrato y la vigencia del mismo se encontraban plenamente demostradas, por tanto, si la demandada pretendía ejercer su derecho de defensa debía realizar el pago de los dineros adeudados en la cuenta de depósitos judiciales para tal efecto. Posteriormente, la madre de la menor interpone acción de tutela contra la providencia aludida. En primera instancia, es confirmada la decisión del Juez Civil, quien adujo que el fallo accionado encuentra respaldo en el parágrafo $2^{\circ}$ del numeral $2^{\circ}$ del artículo 424 del Código de Procedimiento Civil. Una vez desatado el recurso de apelación, sin muchos argumentos, el ad quem confirma la sentencia anterior. La Corte Constitucional, revoca las providencias precedentes, al aducir que los recursos legales existentes son ineficaces para el demandado cuando la causal alegada para la restitución del inmueble es la mora en el pago del canon del arrendamiento, precisamente porque el arrendatario debe consignar los dineros supuestamente adeudados.

En el caso estudiado, la accionante carecía de los recursos económicos para cumplir la carga procesal impuesta por la normatividad, razón por la cual debía prosperar la acción de tutela. Aunado a lo anterior, el Juzgado Civil, debió advertir el posible fraude denunciado por la madre de la menor Johanna Alejandra, consistente 
en la sustracción de la obligación alimentaria por parte del demandante. Al respecto manifestó la Corte:

\begin{abstract}
"Es que el artículo 58 del Código de Procedimiento Civil dota a los jueces de una facultad que debe ser utilizada cuando adviertan colusión o fraude, y consiste en convocar a las personas que puedan resultar perjudicadas, para que hagan valer sus derechos, en cualquier etapa del proceso, sin que para el efecto requieran consignar suma alguna a órdenes del Juzgado, como tampoco mostrar recibos de ninguna clase. De modo que la Jueza accionada, si bien no podía oír a la señora Martínez como demandada, tenía que hacerlo como representante y encargada de la custodia y cuidado personal de Johanna Alejandra. Entonces al omitir ese deber incurrió en vía de hecho y deberá enmendar la actuación". ${ }^{4}$
\end{abstract}

De lo anterior se observa, que el juez civil, así como los jueces de tutela, sustentaron sus escuetos argumentos en el obedecimiento a la norma procesal y en la exigencia de la carga procesal impuesta al demandado. Por su parte, la Corte Constitucional, reconoce que el precepto legal resulta excesivo para el arrendatario que carece de los recursos económicos para efectuar las consignaciones de los cánones de arrendamiento supuestamente adeudados, situación que vulnera el derecho fundamental al debido proceso. La providencia estudiada, es el inicio de un precedente estructurado por parte del Tribunal Constitucional.

En el mismo año, la Corte mediante sentencia T-494-2005, analiza el caso de una madre cabeza de familia y tres menores, que son desalojados de su vivienda en razón a un proceso de restitución de inmueble arrendado iniciado por el padre de los niños, con fundamento en el incumplimiento de un contrato de arrendamiento suscrito por los ex compañeros permanente. El juez civil que conoció el asunto, ordenó la restitución con base en la inobservancia de la carga probatoria impuesta por la norma, sin considerar la intervención realizada por el defensor de familia en representación de los intereses de los niños, quien esbozó los siguientes argumentos:

“(I) Que la pretendida orden de lanzamiento conducía a la violación de los derechos de los niños, los cuales son principalísimos y superiores a cualquier otra norma o institución jurídica (C.P. art. 44); (II) Que el contrato de arrendamiento se suscribió a través de "fuerza" como vicio del consentimiento (C.C. art. 1502); (III) Que existía pleito pendiente en relación con el ingreso del bien objeto de restitución a una posible sociedad patrimonial (C.P.C. art. 170); y finalmente, (IV) Que resultaba aplicable la exceptio non adimpleti contractus por el incumplimiento de las obligaciones alimentarias del señor Ortiz frente a sus 3 menores hijos (C.C. art. 1609)". (Corte Constitucional. Sala Quinta de Revisión. Sentencia T-494 de 2005; M.P. Rodrigo Escobar Gil).

Contra la providencia que ordenó la restitución, el defensor de familia interpuso 
acción de tutela. El juez de primera instancia, concedió la protección constitucional, adujo que la decisión adoptada vulneraba los derechos fundamentales de los niños a la vida digna, al cuidado y a la obligación de protección contra el abandono y la violencia moral. El juez de segunda instancia, revocó la sentencia, esbozó dos argumentos: el derecho a la vivienda digna no es fundamental $\mathrm{y}$, por tanto, no es susceptible de protección mediante acción de tutela, igualmente sostuvo que: en el trámite del proceso de restitución del inmueble arrendado, se cumplieron a cabalidad los pasos inherentes a dicha ritualidad procesal; y que, además, frente a la providencia que resolvió dicho conflicto, no se interpusieron los recursos pertinentes por ley.

La Corte Constitucional al conocer el asunto, manifestó que el juez civil no debió desconocer la legítima intervención del defensor de familia durante el trámite del proceso, cuyo fundamento radicaba en la legitimatio ad processum prevista en el ordenamiento Superior, a favor de las autoridades del Estado constituidas para proteger los derechos de los niños (CP art. 44), bajo el simple argumento de no haberse cancelado los cánones de arrendamiento adeudados por la supuesta arrendataria, señora Ana Elizabeth Gamboa, pues dicha carga -según se ha visto- es únicamente exigible para el demandado, y no para el Defensor de Familia, quien goza de plena capacidad procesal para ejercer las acciones pertinentes ante las autoridades judiciales, en defensa de los derechos de los niños.$^{5}$

Dicha situación, condujo a la configuración de una vía de hecho por defecto procedimental, al extender los efectos de la carga procesal del parágrafo $2^{\circ}$, numeral $2^{\circ}$, del artículo 424 del Código de Procedimiento Civil, al defensor de familia. De igual forma manifestó la Corte, que al juez del caso le correspondía ahondar en la posible nulidad del negocio jurídico que sustentaba la pretensión de restitución, con el objetivo de proteger los derechos fundamentales al debido proceso, a la defensa y a la contradicción de los menores.

En la sentencia analizada se observa una vez más, la inactividad de los operadores judiciales en aplicar los derechos fundamentales, y en la interpretación exegética de la norma procesal sin considerar los fundamentos facticos de la demanda. La Corte Constitucional, por su parte, analiza de manera cuidadosa los hechos que sustentan la acción, e indica de manera clara el alcance del artículo 424 del Código Procedimiento Civil, respecto a la intervención del defensor de familia. Pese a que en el caso estudiado, no se debate la existencia del contrato de arrendamiento, sino su validez, la Corte indica la necesidad de aclarar el asunto, previamente a una orden de restitución, mediante la inaplicación del referido precepto.

Otra providencia de igual importancia emitida por la Corte Constitucional, es la sentencia T-162 del 2005 de la sala sexta de revisión con M.P. Marco Gerardo Monroy Cabra, en ella se resuelve el caso de un poseedor de buena fe, que con el

5 Corte Constitucional. Sala Quinta de Revisión. Sentencia T-494 de 2005; M.P. Rodrigo Escobar Gil. 
beneplácito de sus hermanos habitaba uno de los inmuebles de propiedad de su difunto padre, mientras se adelantaba el proceso de sucesión para adjudicarlo. Sin embargo, uno de los hermanos con el propósito de desalojarlo, decide adelantar proceso de restitución de inmueble arrendado, con base en declaraciones extra juicio rendidas ante notario. El juez de tutela en primera instancia, concede las pretensiones del accionante, al aducir que el Juez Civil pudo hacer uso de la EXCEPCIÓN DE INCONSTITUCIONALIDAD consagrada en el ordenamiento jurídico, con el objetivo de inaplicar la norma procesal, y garantizar el derecho fundamental de defensa. A pesar de la decisión del a quo, el operador judicial en segunda instancia revoca la sentencia precedente, al considerar que para la inaplicación de una norma por vía de excepción de inconstitucionalidad era menester que fuera abiertamente contraria a la Constitución ó a la ley lo que no se daba en el caso sometido a su consideración, pues la constitucionalidad de la norma había sido objeto de estudio por la Corte mediante Sentencia C-070-1993.

La Corte Constitucional, al revisar la acción de tutela, consideró que los mecanismos de defensa del demandado resultaban ineficaces durante el proceso civil, ante la carga procesal impuesta por la normatividad, en razón a que la única forma para hacer efectivo su derecho de defensa sería consignando a órdenes del juzgado los valores supuestamente adeudados al demandante, los cuales se encontraban estimados en una suma superior a diez millones de pesos $(\$ 10.000 .000)$. Uno de los argumentos más relevantes de la Corte en el caso bajo estudio para inaplicar la norma procesal, consistió en manifestar que: "En el caso particular que ahora se somete a su decisión, no procede aplicar la norma que exige al arrendatario demandado cancelar la totalidad de los cánones que se imputan en mora, como requisito para ser oído en el juicio. Empero, esta inaplicación no obedece a la utilización de la figura de la excepción de inconstitucionalidad, como lo propuso el juez de primera instancia, pues, por las razones que arriba se dejaron reseñadas, la Corte ha demostrado que no existe una contradicción objetiva entre dicha regla legal y la Constitución. La razón que en este caso impone inaplicar la disposición estriba en que el material probatorio obrante tanto en el proceso de tutela, como en el civil de restitución, arroja una duda seria respecto de la existencia real de un contrato de arriendo entre el demandante y el demandado, es decir, está en entredicho la presencia el supuesto de hecho que regula la norma que se pretende aplicar". (Corte Constitucional. Sala sexta de revisión. Sentencia T-162 del 2005; M.P. Marco Gerardo Monroy Cabra)

En la providencia estudiada, claramente establece la Corte Constitucional, que la norma procesal se ajusta a la Constitución Política, tal como se expresó en sentencia de constitucionalidad C-085 de 1993. Por lo anterior, no es posible alegar la excepción de inconstitucionalidad por parte del funcionario judicial para inaplicar el precepto legal si no, la existencia de grave duda respecto al supuesto fáctico requerido para aplicarlo. En este caso se observa un avance en los jueces de tutela para proteger los derechos fundamentales, a través del erróneo uso de la figura jurídica mencionada, 
con el propósito de inaplicar la norma y lograr proteger el derecho al debido proceso.

Con posterioridad, la Corte estudia en la sentencia T-035 del 2006 el caso de una sociedad demandada por parte de un secuestre, quien en calidad de auxiliar de la justicia, solicitó mediante proceso judicial la restitución de un inmueble que supuestamente le fue otorgado en arrendamiento. El demandante, nunca presentó contrato de arrendamiento suscrito entre las partes procesales, sin embargo, la demanda fue admitida con la sola manifestación del accionante que actuaba en condición de auxiliar de la justicia y que el contrato se encontraba inmerso en los documentos que anexaba en el escrito de la demanda.

El juez civil, en aplicación del artículo 424 del CPC, emitió sentencia a favor de las pretensiones del demandante, sin considerar las excepciones propuestas por la sociedad. Contra la providencia de restitución, el demandado instauró acción de tutela. El juez de primera instancia la concede, aduce que del acervo probatorio se evidenciaba duda respecto a la existencia del contrato de arrendamiento suscrito entre las partes, por tanto, es preciso no aplicar la norma procesal con el propósito de no menoscabar el derecho fundamental al debido proceso. A su vez, expresó que el juez en el Estado Social de Derecho, no podía cerrar los ojos y aplicar la ley sin consideración a la ostensible vulneración de derechos fundamentales que en una situación particular tal aplicación automática pudiera producir.

El accionado, interpuso recurso de apelación contra la providencia emitida por el a quo, decisión que fue confirmada con base en los mismos argumentos expuesto en primera instancia. La Corte Constitucional, al respectó indicó:

"que la carga procesal, en las circunstancias concretas del presente caso, resulta excesiva, dado el material probatorio allegado al proceso civil y al de tutela, que pone en sería duda la existencia de dicha deuda para con el demandante, la condición de arrendador sustituto de este último y la existencia del contrato de arriendo en sí mismo" (Corte Constitucional. Sala Sexta de Revisión. Sentencia T 035 de 2006; M.P. Marco Gerardo Monrroy Cabra).

Con base en lo anterior, se precisa que por razones de justicia y equidad, en casos excepcionalísimos es posible inaplicar el segundo numeral del parágrafo segundo del artículo 424 de Código de Procedimiento Civil.

En la providencia anterior, a diferencia de aquellas que se han analizado precedentemente, los jueces constitucionales que conocieron de la acción de tutela, ajustaron sus providencias a la Constitución Política y, por ende, a los derechos fundamentales al debido proceso y acceso a la administración de justicia. La Corte Constitucional, de manera clara indicó, que en los casos en que se inicie el proceso de restitución de inmueble arrendado, cuando la causal alegada sea la mora en el pago de los cánones de arrendamiento, es viable la inaplicación del precepto procesal, cuando exista duda respecto a la existencia del contrato de arrendamiento.

Para culminar con la presentación de las providencias revisadas por la Corte Constitucional, a continuación se expone el caso analizado en la sentencia T-1082 
proferida en el año 2007; en ella se estudia la situación de un señor que es demandado en un proceso de restitución de inmueble arrendado con base en la causal de mora en el pago de los cánones de arrendamiento. El demandante fundó sus pretensiones, aduciendo ser titular de los derechos derivados del contrato de arrendamiento como producto de una cesión efectuada por el anterior propietario del inmueble. El demando, alegó no ostentar la calidad de tenedor, si no de poseedor del inmueble, en razón a la inexistencia del contrato de arrendamiento. A pesar de lo anterior, el juzgado que conoció el proceso, ordenó proferir sentencia de restitución por incumpliendo de la carga procesal del artículo 424 del CPC. El juez de tutela en primera instancia, negó el amparo a los derechos fundamentales, y justificó que el Juez Civil obró con apego a la ley sin desconocimiento de las oportunidades y los recursos que ésta brinda a las partes para su defensa. A su vez, el juez en segunda instancia confirmó la providencia, expresando de igual manera que el accionante no podía ser escuchado dentro del proceso, por incumplir con la carga procesal exigida por el artículo 424 del CPC.

La Corte Constitucional, en una de las mejores providencias que define el tema objeto de la disertación, concedió el amparo constitucional con base en los argumentos que a continuación se esbozaran. En primer lugar sustenta la Corte, que el condicionamiento impuesto por la norma procesal no afecta el núcleo esencial de los derechos al debido proceso y acceso a la administración de justicia, pues el arrendatario puede ser escuchado dentro del proceso, al presentar los recibos de pago de los tres últimos periodos o consignar a órdenes del juzgado los dineros supuestamente adeudados, con la finalidad de brindar celeridad y eficacia a un proceso de naturaleza abreviada.

Sin embargo, cuando hay serias dudas sobre la existencia del contrato de arrendamiento, ya sea porque éstas han sido alegadas razonablemente por las partes o, porque el juez así lo constató de los hechos que se encuentran probados, no debe exigírsele al demando la carga procesal en cuestión,

"lo anterior por cuanto no existe certeza sobre la existencia de uno de los presupuestos fácticos de aplicación de la norma, en este caso el contrato de arrendamiento" (Corte Constitucional. Sala Séptima de Revisión. Sentencia T- 1082 de 2007; M.P. Humberto Antonio Sierra Porto).

La Corte de manera terminante, le ilustra al operador judicial que en el desarrollo de su actividad judicial, están llamados a justificar racionalmente la toma de decisiones, para tal fin pueden hacer uso de diversos tipos de argumentaciones jurídicas, entre los que encontramos el modelo de la subsunción, según el cual en los supuestos en los que la disposición no ofrece mayores dificultades interpretativas el operador jurídico realiza un análisis de la realidad que se encuentra probada en el proceso y la compara con el supuesto de hecho de la norma, a fin de determinar si ella encaja en el enunciado normativo que otorga una consecuencia jurídica y sirve para la resolución del caso concreto. (Corte Constitucional. Sala Séptima de Revisión. Sentencia T- 1082 de 2007; M.P. Humberto Antonio Sierra Porto). 
De esta manera, el fallador inmerso en una actuación judicial, debe analizar de manera concienzuda los hechos sustento de la demanda con base en el caudal probatorio, con el objetivo de verificar que la situación fáctica encaje en la disposición normativa que se pretenda aplicar para solucionar el caso concreto. Actuar de una manera diferente, conlleva a la vulneración de los derechos fundamentales al debido proceso y acceso a la administración de justicia, al emitirse una providencia sin un verdadero sustento jurídico. Para la Corte, lo importante no es el modelo de argumentación jurídica que utilicen los funcionarios judiciales, sino que otorguen racionalidad a sus decisiones con base en los valores, principios y derechos constitucionales, de tal manera que no desborden sus facultades constitucionales y legales. Así mismo, se puede afirmar de la providencia analizada, que la carga procesal cuestionada se ajusta a la Carta Magna, por ende, la decisión de no aplicar el precepto legal, no constituye un cambio jurisprudencial ni desconoce los efectos de cosa juzgada del fallo que decidió la constitucionalidad de la norma aludida.

Con base en lo visto hasta el momento, se puede aseverar que algunos jueces civiles, aplican aún ciegamente la norma procesal, apartándose del alcance que la Corte Constitucional le ha otorgado a los derechos fundamentales al acceso a la administración de justicia y debido proceso, con el único argumento de la obediencia al canon legal. Es evidente, que no existe en la jurisdicción civil, con base en las sentencias revisadas por la Corte, un argumento fuerte y estructurado para alejarse del precedente constitucional, tal y como en líneas anteriores se planteó.

Por su parte los jueces constitucionales, es decir aquellos encargados de resolver la acción de tutela y de proteger los derechos fundamentales quebrantados por la providencia judicial, de manera progresiva y con el transcurso del tiempo se han ajustado al precedente vertical de acuerdo a los racionamientos del Tribunal Constitucional. En principio, al aducir equívocamente la inaplicación de la norma vía excepción de inconstitucionalidad, sin embargo, se observaba en ellos la intención de salvaguardar los preceptos y garantías de la Carta Maga. La Corte aclaró el punto, al explicar que el mandato procesal, se ajusta a la Constitución Política, de acuerdo a la sentencia de constitucionalidad mediante la cual se declaró la exequibilidad del artículo. Igualmente, es puntual destacar que en ocasiones, quien concede el mecanismo constitucional, es el juez de tutela de primera instancia, y su decisión con miras a proteger los derechos fundamentales, es revocada por el superior jerárquico, bien de circuito o tribunal de distrito judicial. En esa medida, no sólo existe discrepancia respecto a las decisiones emitidas por la Corte, sino de igual manera, entre los operadores judiciales de conformidad con la estructura jerárquica en que se encuentran organizados.

Por otra parte, se reitera que la inaplicación del numeral 2 del parágrafo 2 del artículo 424 del CPC, se realiza en aquellos supuestos en que se evidencia serias dudas respecto a la existencia del contrato de arrendamiento, verbigracia cuando el demandado no es arrendatario, si no que funge como poseedor material del inmueble objeto de la litis o, en aquellos casos en que se pacta como forma de pago de cuota 
alimentaria, la posibilidad de habitar el bien cuya restitución se demanda. Igualmente se destaca, que la posible inexistencia del contrato de arrendamiento no es el único motivo para no aplicar la norma, existe la posibilidad que el contrato efectivamente haya sido suscrito, y, sin embargo, adolezca de nulidad o tenga como propósito defraudar el cumplimiento de una providencia judicial. En todos los casos, el juez de conocimiento debe evaluar la situación fáctica que se pone a su consideración.

En conclusión, la ratio decidendi plasmada en las providencias de la Corte Constitucional, que llevó a la creación de la sub-regla presentada, es decir, a la inaplicación del canon procesal, cuando se presenta duda respecto a la existencia del contrato de arrendamiento, obedece a la aplicación de criterios de justicia y equidad en los casos sometidos a decisión del operador judicial, de tal manera que pese a la constitucionalidad de la norma, no se extiendan los contenidos del precepto a la situaciones fácticas no contempladas en ella. En caso contrario, se conculcarían los derechos fundamentales del demandado al debido proceso y acceso a la administración de justicia. La carga procesal, sustentó la Corte en sus sentencias de tutela, se ajustan a los principios del derecho probatorio y le otorgan mayor eficacia y celeridad al proceso judicial.

Con base en la exposición realizada hasta el momento, es indiscutible que el conflicto procesal generado por el artículo 424 del Código de Procedimiento Civil se mantiene en el ordenamiento jurídico, pese al intento de la Corte en remediarlo mediante la ratio decidendi decantada a través de los diversos casos que ha revisado. A través de esta labor unificadora, la Corte ha dotado a los jueces civiles y constitucionales de reglas claras para interpretar el precepto legal conforme a la Constitución Política, sin embargo, los operadores judiciales, como se pudo observar en líneas atrás, se alejan del precedente constitucional, bien por desconocimiento, o porque deciden apartarse de lo conceptuado por la Corte sin una debida argumentación jurídica. Por lo anterior, la acción de tutela se ha convertido en la herramienta procesal en cabeza del arrendatario demandado, para lograr ser escuchado dentro del proceso, situación que contraviene el orden del sistema jurídico.

Para finalizar, es pertinente afirmar que remediar el asunto es una ardua tarea, pues la norma fue declarada exequible sin condicionamiento alguno por parte del Tribunal Constitucional, tanto así, que dicha corporación ha sostenido su concepto mediante los fallos de tutela en los que se ha estudiado el tema, al indicar que la norma se ajusta a la Carta Magna y su inaplicación se debe a la falta de correspondencia entre el precepto y el escenario fáctico sometido a decisión del juez. Dicha situación genera inseguridad jurídica, y vulnera el derecho a la igualdad de los arrendatarios que cumplen los requisitos para no exigirles la carga procesal cuestionada, pues la decisión de escuchar al demandado depende de la voluntad del operador judicial, por ende, similares eventos pueden ser fallados en diversa forma según el criterio del administrador de justicia.

Siendo así, a través del presente escrito, se da a conocer la ratio decidendi de la Corte Constitucional para la inaplicación del canon legal, con el objetivo, que 
esperamos no sea ilusorio, el administrador de justicia los utilice como instrumento para garantizar los derechos fundamentales al debido proceso y acceso a la administración de justicia. En este punto, es válido traer a colación, la siguiente frase del Doctor Jorge Enrique Figueroa, plasmada en su libro Interpretación Constitucional y Decisión Judicial:

"El juez como líder social debe tener las siguientes características: ser un visionario, ser un idealista, valiente, dispuesto al cambio, dispuesto a trascender su existencia mediante el compromiso, que haga de sus actos de vida actos de calidad, asumir su espiritualidad y su integridad como ser, humilde y tener por valor supremo la justicia" (Figueroa; 2001; 70).

Hasta que lo anterior suceda, y la protección de la Constitución Política se convierta realmente en el objetivo del funcionario judicial, es válido afirmar, que sólo a través de una reforma al canon procesal, es posible garantizar los derechos fundamentales conculcados, y mencionados a lo largo del presente texto: El Debido Proceso y Acceso a la Administración de Justicia.

\section{REFERENCIAS}

Gómez, César. (2008). De los principales contrato civiles, 4ª . ed. Editorial Temis S.A Bogotá

López, Hernán Fabio. (2004). Procedimiento Civil Parte Especial, Dupre Editores. Agudelo, Martín. (2005). El debido Proceso, en: Revista Opinión Jurídica. Vol. 4, No. 7. Medellín - Colombia. Facultad de derecho Universidad de Medellín,

García, Mauricio; Rodrigo, Uprimmy. ¿Qué hacer con la tutela contra sentencias? Revista de la Academia Colombiana de Jurisprudencia. Bogotá, 2004.

Gómez Lara. Cipriano. (1990). La protección de los derechos fundamentales. Revista Universitaria de Derecho Procesal. Universidad de Educación a Distancia. Madrid.

Ramírez Carvajal, Diana María. (2007). A propósito de la Justicia Material (reflexiones sobre la justicia en el proceso vs la justica material), en: Revista Opinión Jurídica. Vol. 6, No. 12. Medellín - Colombia. Facultad de derecho Universidad de Medellín.

Quinche, M. (2007). Vías de hecho - acción de tutela contra providencias judiciales. Bogotá. Editorial Universidad del Rosario.

Bibliografía complementaria

Agudelo, M. (2005). El debido Proceso, en: Revista Opinión Jurídica. Vol. 4, Nro. 7. Medellín - Colombia. Facultad de Derecho, Universidad de Medellín. 
Cabrera, M; Leal, H; Sáenz, L. (2001). Contrato de arrendamiento y proceso de restitución del inmueble. Cuarta edición. Bogotá D.C. Editorial Leyer.

Gómez, C. De los principales contratos civiles. 4ª Edición. Bogotá. Editorial Temis.

Fierro, H. (2004). Tutela y vías de hecho. Bogotá. Editorial Leyer.

Figueroa, J. (2001). Interpretación constitucional y decisión judicial. Bogotá. Editorial Leyer.

García, M; Uprimmy, R. (2004). ¿Qué hacer con la tutela contra sentencias?, en: Revista de la Academia Colombiana de Jurisprudencia. Bogotá.

Gómez, C. (1990). La protección de los derechos fundamentales. En: Revista Universitaria de Derecho Procesal. Universidad Nacional de Educación a Distancia. Madrid.

Henao, J. (2006). Derecho procesal constitucional protección de los derechos constitucionales. Segunda. Bogotá. Edición Editorial Temis S.A.

Hernández, J. (2001). Poder y constitución. El nuevo constitucionalismo colombiano. Bogotá. Editorial Legis.

López, H. (2004). Procedimiento Civil Parte Especial. Bogotá. Editorial Dupre Editores.

López, D. (2006). El derecho de los Jueces. 2a . Edición. Bogotá. Editorial Legis.

Villamil, E. (1999).Teoría constitucional del Proceso. Bogotá. Ediciones Doctrina y Ley Ltda.

Ramírez, D. (2007). A propósito de la Justicia Material (reflexiones sobre la justicia en el proceso vs. la justica material), en: Revista Opinión Jurídica. Vol. 6, No. 12. Medellín - Colombia. Facultad de derecho Universidad de Medellín.

Código de Procedimiento Civil; 2009; artículo 424 (Reformado. Decr. 2282 de 1989, art 1, Modificado. Ley 794 de 2003 artículo 44)

Corte Constitucional. Sala Plena. Sentencia C-070 de 1993; M.P. Eduardo Cifuentes Muñoz

Sentencia C-037 de 1994, M.P. Antonio Barrera Carbonell.

Sentencia C-037 de 1996, M.P. Vladimiro Naranjo Mesa

Sentencia SU 047 de 1999

Sala séptima de Revisión. Sentencia T-830 de 2004; M.P.(E) Rodrigo Uprimny Yepes

Sala Quinta de Revisión. Sentencia T-494 de 2005; M.P. Rodrigo Escobar Gil

Sala sexta de revisión. Sentencia T-162 del 2005; M.P. Marco Gerardo Monroy Cabra

Sala Tercera de Revisión. Sentencia T-292 de 2006, M.P. Manuel José Cepeda Espinosa 
Sala Sexta de Revisión. Sentencia T 035 de 2006; M.P. Marco Gerardo Monrroy Cabra.

Sala Séptima de Revisión. Sentencia T-1082-2007; M.P. Humberto Antonio Sierra Porto. 